\title{
A "ONDA VERDE": análise discursiva dos programas eleitorais da campanha de Marina Silva à presidência ${ }^{1}$
}

\author{
The "Green Wave": discursive analysis of electorals programs Marina Silva's \\ campaign for president
}

\author{
MARCO TÚLIO SOUSA ${ }^{2}$ \\ CÍCERO COSTA VILLELA ${ }^{3}$
}

Resumo: Neste trabalho, pretendemos analisar um dos principais elementos da campanha de Marina Silva à presidência, o Horário de Propaganda Eleitoral Gratuito. Tentamos compreender de que forma seu discurso articula diferentes formações discursivas - como a ecológica e a religiosa - na produção de sentido para a política e para sua atuação. Para isso, mobilizamos o aparato analítico e conceitual da Análise de Discurso Franco-Brasileira na tentativa de entender os processos de produção de sentido e perceber quais são as bases ideológicas que permitem a produção das falas de Marina Silva.

Palavras-chave: discurso; ecologia; horário eleitoral; linguagem.

Abstract: In this paper, we intend to analyse one of the main elements of political campaigns, the Free Electoral TV Program, of the candidate PV candidate for the Presidency of Brasil, Marina Silva. We attempted to comprehend in what way her discourse articulates different discursive formations - such as the ecological and religious ones - in the production of sense to the politics and to her performance. To do

1Trabalho apresentado no GT de Comunicação e Linguagens do IV Seminário de Pesquisas em Mídia e Cotidiano: Discursos Midiáticos e Práticas Sociais. Evento organizado pelo programa de Pós-Graduação em Mídia e Cotidiano da Universidade Federal Fluminense (UFF). Local: Universidade Federal Fluminense (UFF), Niterói (RJ), 2012.

${ }^{2}$ Mestrando pelo Programa de Pós-Graduação em Comunicação da UFMG. Pesquisador do Núcleo de Estudos Tramas Comunicacionais. Bolsista da Coordenação de Aperfeiçoamento de Pessoal de Nível Superior - CAPES. Sua pesquisa envolve aspectos discursivos em produtos midiáticos de denominações religiosas pentecostais. E-mail: marcotuliosousa@hotmail.com.

${ }^{3}$ Graduando em Comunicação Social/ Jornalismo pela UFJF. Bolsista do Programa de Educação Tutorial no período de 2008-2012, atuando em ensino, pesquisa e extensão. Realiza pesquisas em Comunicação Política e Análise de Discurso. E-mail: cicerovillela@hotmail.com. 
so, we mobilised the analytical and conceptual apparatus of the French-Brazilian Discourse Analysis as an attempt to understand the processes of production of sense and perceive what ideological bases permit the production of Marina Silva's speeches.

Keywords: discours; ecology; political advertasing; language.

\section{Introdução}

O presente artigo tem como objetivo analisar a construção do discurso político-ecológico da candidata do Partido Verde (PV) à Presidência da República em 2010, Marina Silva. Para isso, adotamos como lugar de observação os programas televisivos do Horário Gratuito de Propaganda Eleitoral (HGPE): eles ocupam uma posição central nas campanhas, já que os partidos políticos passam a ter acesso direto aos meios de comunicação sem a mediação de instâncias jornalísticas.

Marina alcançou 19.636.359 votos - quase 20\% do total, numa campanha cujo crescimento na reta final foi nomeado pelos jornais como “onda-verde”. Seu principal tema foi exatamente a ecologia e seus termos correlatos (como sustentabilidade) e, embora com tempo limitado de TV (1'32'’) e dispondo de poucos recursos (mas com grande presença também nas redes sociais), a campanha da candidata foi decisiva para que houvesse segundo turno naquele pleito.

Neste trabalho, analisaremos os programas a fim de perceber as formações discursivas que sustentaram os dizeres de Marina naquela eleição. Busca-se apontar como suas falas produziram sentido e a partir de quais posições de enunciação elas foram construídas.

\section{A causa ecológica}

O termo "ecologia” se refere às relações que os seres vivos estabelecem com o meio onde vivem. Esta é a definição que encontramos no Dicionário Aurélio (2004). Em uma leitura discursiva, podemos considerar os dicionários lugares de estabilização de sentido, visto que nos informam das acepções supostamente admitidas de uma determinada palavra. 
No entanto, a língua está sujeita às vicissitudes da história. Palavras adquirem outros sentidos e são empregadas de outra forma. Atualmente, o significante “ecologia” tem sido associado a medidas de proteção ao meio ambiente. O tema ocupa hoje espaços de destaque nos meios de comunicação e é discutido por diversos setores da sociedade como empresas, movimentos sociais, cientistas e políticos.

De acordo com Ione Goés (s.d, p. 1), até a década de 50 [do século passado], as preocupações ambientais estavam restritas aos meios científicos. As principais questões se referiam à preservação das espécies e do meio ambiente. Cenário que muda nos anos 60, com a contracultura. De acordo com a referida autora:

\begin{abstract}
A partir da década de 60 emergem, com a contra-cultura, uma série de movimentos sociais trazendo, não só a crítica ao modelo dominante de produção, mas também ao modo de vida. Surgem, então, os movimentos das mulheres, dos negros, dos homossexuais, dos pacifistas e, entre eles, os movimentos ecologistas. (GOÉS, s.d, p.1)
\end{abstract}

Na década seguinte, foi a vez de os políticos terem um maior envolvimento com a causa ambiental. Nos anos 80, ela chega aos setores econômicos, principalmente por meio das propostas de “desenvolvimento sustentável”, campanhas publicitárias educativas de reciclagem e a criação dos chamados “produtos verdes”.

De acordo com Castells (2006), o movimento ecológico foi o que mais alcançou notoriedade nos últimos tempos. Na década de 90 , cerca de " $80 \%$ dos norteamericanos e dois terços dos europeus se consideram ambientalistas; candidatos e partidos políticos dificilmente conseguem se eleger sem 'verdejarem' suas plataformas” (CASTELLS, 2006, p. 141).

No Brasil, um dos marcos da causa ambiental foi a criação do Partido Verde (PV) em 1986. Segundo Célia Dias (2002), rapidamente o partido se tornou o principal articulador da questão ambiental no país.

O PV foi, no período referido (1985-1989), o enunciador da principal interpelação ambiental da esquerda brasileira (...). O partido trouxe para o debate de então a discussão ecológica internacional e tentou associá-la às questões prioritárias do cenário político-social brasileiro: crítica ao modelo de desenvolvimento e à destruição do ambiente natural, fruto desse modelo; crítica à forma de fazer política; dentre outras. (DIAS, 2002, p. 104) 
A orientação de esquerda dos fundadores do partido não veio a se refletir em muitos de seus sucessores, o que desde então vem provocando inúmeras divergências no partido. Uma das mais conhecidas resultou na saída de Carlos Minc para o PT. De acordo com Dias (2002)

\begin{abstract}
Um dos grandes problemas "antinômicos” do discurso político do PV esteve presente justamente nesse corte "classista". Os discursos eram ambíguos, porque nem todos do partido (nem do movimento) compartilhavam essa abordagem. Alguns negavam a luta de classes e até a participação ambientalista na política, atribuindo à política a destruição da natureza; nesse caso, prevalecia uma confusão de idéias que tornava alvo a teoria marxista, e não sua prática/ação. (DIAS, 2002, p. 105)
\end{abstract}

Este é um dos pontos centrais deste artigo, já que pretendemos analisar os sentidos que a “política” e a própria questão ecológica assumem nos programas eleitorais da candidata do PV. Por ora, o que podemos afirmar é que essa pluralidade de atores que versam sobre a causa contribui para a existência de um conjunto variado de posicionamentos (e sentidos) sobre a questão. E o tema facilita esse tipo de apropriação, uma vez que

o mesmo princípio básico ('respeito a Natureza') pode-se articular em uma infinidade de posições (respeito aos animais, contra a humanidade; respeito a humanidade, considerada parte da natureza, dentre outras), e de cada uma delas podem derivar diferentes representações da política e das possíveis estratégias de ação. (DIAS, 2002, p. 101)

O interesse pelo mesmo tema implica que os grupos acima citados se relacionem, seja para se enfrentarem ou agirem em parceria. A ciência atua sempre como autoridade máxima, sendo sempre requisitados pelos demais grupos como poderoso recurso argumentativo. Ela diz o que é certo e errado, ocupando espaço privilegiado nos posicionamentos dos demais setores. No caso das relações que os outros grupos estabelecem entre si, a questão é mais complicada. Ora se apoiam, ora lutam entre si.

De acordo com Agripa Faria Alexandre (2003), parte dos movimentos sociais brasileiros que tem a ecologia como bandeira perdeu sua radicalidade, o que 
facilitou a aproximação com empresas e políticos que defendem medidas de preservação do meio ambiente que não atrapalhem o desenvolvimento econômico. Deste tipo de pensamento surge o conceito de "desenvolvimento sustentável”, que preconiza a tese da viabilidade de atividades econômicas que não provoquem grandes danos ao meio ambiente ou que procurem compensar a "agressão" a partir de ações de revitalização do ecossistema.

Em nosso estudo, temos uma campanha eleitoral protagonizada por uma candidata de histórica identificação com a esquerda (Marina sempre foi militante do PT, saindo do mesmo em 2009), e filiada a um partido que, como vimos anteriormente, enfrenta problemas internos quanto ao seu alinhamento ideológico. O que aproxima a candidata e o partido é a identificação com a causa ecológica. Mas que causa ecológica é essa? Quais os sentidos de “ecologia” e “política” emergiram nos programas eleitorais de Marina naquela campanha? Procuraremos responder a essas questões com base na análise de discurso.

\section{Metodologia de Análise}

A análise dos programas eleitorais de Marina Silva será feita em duas etapas. Em um primeiro momento, identificaremos os principais eixos temáticos de sua campanha. Dessa forma, pretendemos mostrar o escopo geral do percurso eleitoral, apresentando os temas recorrentes e relacionando-os à posterior análise discursiva.

Neste trabalho, utilizaremos como metodologia a Análise de Discurso (doravante $\mathrm{AD}$ ), sobretudo a de origem franco-brasileira, tendo Michel Pêcheux e Eni Orlandi como principais referências. Partindo da análise de textualidades verbais ${ }^{4}$ (falas, jingles e frases escritas que aparecem nos programas), pretendemos verificar como se deu o funcionamento do discurso de Marina Silva. Ou seja, a partir de quais posições se

4 Para a Análise de Discurso, imagem, corpo e linguagem verbal são consideradas materialidades significantes. Assim, poderíamos dizer que cada uma delas constituem textualidades atravessadas por formações discursivas (FD), refletindo, dessa forma, aspectos ideológicos. Não obstante, especificamente neste texto daremos maior atenção à materialidade verbal, reservando uma investigação mais aprofundada das outras dimensões citadas em trabalhos posteriores. 


\title{
ecc DiAno
}

produziu sentido, que formações discursivas atravessaram os dizeres, e, por fim, quais valores ideológicos embasaram os enunciados em questão.

Antes de nos atermos ao material empírico, faz-se necessária uma discussão acerca do referencial teórico-metodológico adotado. A AD surgiu na década de 60 , na França, em um espaço de discussões criadas pelo entrecruzamento de três domínios: a Linguística, o Marxismo e a Psicanálise. Contudo, não há na AD uma pretensão de ser uma síntese do conhecimento desses três campos, já que ela se utiliza de ferramentas e conceitos oriundos destes domínios, mas interpelada por outras questões,

\begin{abstract}
não se reduz ao objeto da Linguística, nem se deixa absorver pela Teoria Marxista e tampouco corresponde ao que teoriza a Psicanálise. Interroga a Linguística pela historicidade que ela deixa de lado, questiona o Materialismo perguntando pelo simbólico e se demarca da Psicanálise pelo modo como, considerando a historicidade, trabalha a ideologia como materialmente relacionada ao inconsciente sem ser absorvida por ele. (ORLANDI, 2005. p.20)
\end{abstract}

O trecho acima nos remete à questão: o que é discurso nessa abordagem? Discurso pode ser definido como "efeito de sentidos entre locutores" (ORLANDI, 2005 p.21). O discurso é a forma material em que a ideologia se materializa. O discurso é parte constitutiva do sujeito e do mundo social e não temos controle absoluto sobre os sentidos que produzimos. Assim, para a $\mathrm{AD}$, se as palavras fazem sentido é porque em algum momento anterior elas já fizeram sentido, de modo a formar redes de memória e de esquecimento, adquirindo assim algum tipo de regularidade.

Contudo, tais regularidades não são permanentes e imutáveis. Assim como na linguística, a $\mathrm{AD}$ entende que a língua tem uma ordem própria, mas acrescenta que tal ordem está sujeita às oscilações da História. Ou seja, os sentidos de uma palavra não são imutáveis e o indivíduo não tem pleno domínio sobre tais transformações. De acordo com Michel Pêcheux (1997),

todo discurso é o índice potencial de uma agitação nas filiações sóciohistóricas de identificação, na medida em que ele constitui ao mesmo tempo um efeito dessas filiações e um trabalho (mais ou menos consciente, deliberado, construído ou não, mas de todo modo atravessado pelas determinações inconscientes) de deslocamento no seu espaço; não há 
identificação plenamente bem sucedida, isto é, ligação sócio-histórica que não seja afetada, de uma maneira ou de outra, por uma 'infelicidade' no sentido performativo do termo - isto é, no caso, por um 'erro de pessoa', isto é, sobre o outro, objeto de identificação. (PÊCHEUX, 1997, p. 56, grifo do autor)

Logo, o que está colocado é que as palavras não possuem sentido em si, mas que estes são produzidos pelo jogo das posições ideológicas que elas colocam em cena e, consequentemente, pela historicidade e situação de comunicação. Isso nos leva a conceituar a noção de Formação Discursiva (doravante FD).

A noção de FD aparece na Análise de Discurso primeiramente no texto conjunto de Pecheux e Fuchs (1968). O conceito é desenvolvido posteriormente em “Semântica e Discurso” (1975). A FD pode ser definida como uma regionalização da memória discursiva. Ela determina aquilo que pode ser dito e de que forma pode ser dito. Além disso, marca posições - dadas em determinadas conjunturas sócio-históricas - que os sujeitos assumem no jogo discursivo. Dessa forma, podemos afirmar que uma mesma palavra pode possuir sentidos diferentes de acordo com a formação discursiva que a atravessa (PECHEUX, 1997).

\footnotetext{
O discurso se constitui em seus sentidos porque aquilo que o sujeito diz se inscreve em uma formação discursiva para ter um sentido e não outro. Por aí podemos perceber que as palavras não têm um sentido nelas mesmo, elas derivam seus sentidos das formações discursivas em que se inscrevem. As formações discursivas, por sua vez, representam no discurso as formações ideológicas. Desse modo, os sentidos sempre são determinados ideologicamente. (ORLANDI, 2005. p. 43)
}

Podemos afirmar que a FD é responsável por tornar os sentidos evidentes, criando uma ilusão de transparência. Esse é um dos efeitos ideológicos elementares. O outro efeito ideológico é o da evidência do sujeito, que também deriva da ideologia. Entendemos o conceito de ideologia não como ocultação da realidade, mas como mecanismo de ligação entre linguagem e mundo.

Apresentamos os dois conceitos principais que estarão sendo mobilizados na tentativa de apresentar os possíveis sentidos dos discursos de Marina Silva. Não pretendemos mostrar o "que” ela quis dizer, mas queremos dar conta do "como" seu 
discurso produz sentido por meio das articulações que nele se realizam. Assim, não faremos uma interpretação definitiva e única do que ela diz, mas tentaremos identificar alguns sentidos que emergem de seus dizeres.

Antes de entrarmos na análise discursiva, expomos no próximo item uma tabela dos programas eleitorais conforme os temas que foram trabalhados em cada um deles. Dessa maneira, teremos uma ideia geral do percurso da campanha da candidata e poderemos inferir que temas foram mais trabalhados, bem como a relação que eles estabelecem com a análise posterior.

\section{Uma campanha ecológica}

A campanha eleitoral de Marina Silva na TV teve como temas principais de discussão a Ecologia e a Disputa Eleitoral. Na sequência, encontramos Saúde e Educação. A tabela abaixo fornece um quadro panorâmico das temáticas dos programas da candidata do PV.

\begin{tabular}{|c|c|c|}
\hline \multicolumn{3}{|c|}{ Distribuição temática do Horário Eleitoral de Marina Silva } \\
\hline Programa & Tema Principal & Outros \\
\hline $1^{\circ}-17 / 08 / 2010$ & Ecologia & Não Há \\
\hline $2^{\circ}-19 / 08 / 2010$ & História de Vida & Ecologia \\
\hline $3^{\circ}-21 / 08 / 2010$ & Não há um tema principal & $\begin{array}{lr}\text { Vários } & \text { (Ecologia, } \\
\text { Educação, } & \text { Saúde, } \\
\text { Segurança) } & \end{array}$ \\
\hline $4^{\circ}-24 / 08 / 2010$ & Educação & \\
\hline $5^{\circ}-26 / 08 / 2010$ & Educação & \\
\hline $6^{\circ}-28 / 08 / 2010$ & Saúde & \\
\hline $7^{\circ}-31 / 08 / 2010$ (Tarde) & Saúde & \\
\hline $8^{\circ}-31 / 08 / 2010$ (Noite) & Disputa Eleitoral & Ecologia \\
\hline $9^{\circ}-02 / 09 / 2010$ (Noite) & Saúde & \\
\hline $10^{\circ}-02 / 09 / 2010$ (Tarde) & Casas de Marina & \\
\hline $11^{\circ}-07 / 09 / 2010$ & $\begin{array}{ll}\text { Ecologia, } & \text { Corrupção, } \\
\text { Vida Política } & \\
\end{array}$ & \\
\hline $12^{\circ}-09 / 09 / 2010$ & Ecologia & Disputa Eleitoral \\
\hline $13^{\circ}-14 / 09 / 2010$ & Ecologia & Disputa Eleitoral \\
\hline $14^{\circ}-16 / 09 / 2010$ & Ecologia & Disputa Eleitoral \\
\hline
\end{tabular}




\begin{tabular}{|l|l|l|}
\hline $15^{\circ}-18 / 09 / 2010$ & Ecologia & História de Vida \\
\hline $16^{\circ}-21 / 09 / 2010$ & Disputa Eleitoral & Educação \\
\hline $17^{\circ}-23 / 09 / 2010$ & $\begin{array}{l}\text { Ecologia, Disputa } \\
\text { Eleitoral }\end{array}$ & \\
\hline $18^{\circ}-25 / 09 / 2010$ (Tarde) & $\begin{array}{l}\text { Ecologia, Disputa } \\
\text { eleitoral e Educação }\end{array}$ & \\
\hline $19^{\circ}-25 / 09 / 2010$ (Noite) & Disputa Eleitoral & \\
\hline $20^{\circ}-30 / 09 / 2010$ (Tarde) & Disputa Eleitoral & \\
\hline $21^{\circ}-30 / 09 / 2010$ (Noite) & Resumo da Campanha & \\
\hline
\end{tabular}

A tabela acima pretende dar conta dos principais eixos temáticos abordados nos programas eleitorais de Marina Silva. Trabalhamos com aquilo que chamamos de “Temas Principais” e “Outros”. Essa distinção se baseia no tempo em que o assunto foi abordado no programa. A ausência de "temas secundários" indica que o programa foi inteiramente dedicado ao "tema principal".

Analisando a tabela, percebemos que o tema Ecologia foi o mais recorrente nos programas. Dos 21 programas analisados ele apareceu em pelo menos 11 programas (8 como tema principal), o que indica que cerca de 52\% dos programas de Marina Silva trataram, de alguma forma, do assunto. O tema Disputa Eleitoral apareceu em 9 programas (42\%), sendo o principal em 3 deles.

A educação foi trabalhada em 5 programas (21\%). Outra temática abordada foi Saúde, que figurou em -5 edições (21\%), sendo 3 exclusivas. Segurança Pública aparece em 1 programa, mas de forma secundária. Outros temas que apareceram nos programas foram: História pessoal, tendo sido um programa dedicado ao tema; Casa de Marina e Corrupção. Há um fato a ser comentado acerca de um assunto que não está indicado na tabela. O tópico Economia não aparece de forma direta em nenhum programa. Contudo, ele perpassa sempre as discussões do programa quando se trata de ecologia.

Apresentados esses dados, podemos perceber o quanto a pauta ecológica é recorrente à candidata, o que é explicável pela sua história pessoal e política (exministra do meio ambiente) e pelo seu partido (Partido Verde). É interessante notar a maneira como o tema ecologia se cola a outros com os quais não possui uma relação direta - como corrupção, por exemplo. Pontuadas estas questões, passemos à análise 


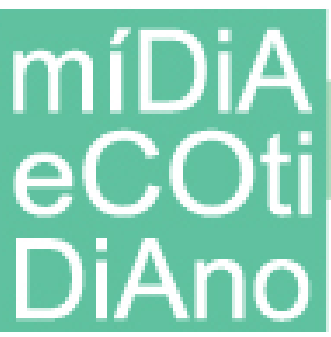

dos textos verbais dos programas.

\section{Análise Discursiva do programa}

Para fins de sistematização, optamos por dividir a análise a partir de dois eixos principais em torno dos quais se alinham os discursos que emergem dos textos em questão: uma identificação plena entre política e ecologia, que deixa entrever uma postura de reafirmação do capitalismo; e um tensionamento em que se revela uma tentativa de Marina em se mostrar como uma pessoa “do povo”, ao mesmo tempo em que há um certo distanciamento da participação popular em seus programas. Estes dois eixos estão profundamente articulados em um discurso religioso de tom messiânico que aparece de maneira recorrente nas edições analisadas.

\section{Política suja, Ecologia limpa}

Antes de analisarmos os enunciados verbais dos programas eleitorais da candidata Marina Silva, é interessante fazermos uma descrição geral da dinâmica dos programas. Marina possuía pouco tempo para fazer campanha na TV, cerca de 1'32" , isso se deve à lei eleitoral que determina o tempo de acordo com o número de cadeiras na câmara de cada coligação.

A maioria dos programas procura apresentar a candidata por meio de sua história e da sua relação com as questões ambientais, além de dar voz a celebridades que a apóiam. O padrão de apresentação de suas propostas é basicamente a fala direta para a câmera, criando um efeito de proximidade com o espectador. Utilizam-se também de falas em off, ilustradas por imagens.

Outro artifício bastante usado é o da simulação de participação popular. Em algumas edições, a candidata aparece em meio a pessoas comuns, que fazem perguntas sobre problemas que elas enfrentam no cotidiano. Contudo, a resposta não é dada de imediato, junto aos cidadãos. Marina sempre responde dentro do estúdio. Embora se 


\section{ecd DiAno}

revele uma tentativa de aproximação, o fato de não responder no momento seguinte ao da questão acaba por sugerir certo distanciamento.

Com uma recorrência acentuada, celebridades do mundo artísticas e especialistas da academia participam dos programas. Eles trazem algum tipo de diagnóstico sobre problemas sociais ou manifestam seu apoio à candidata. Na maioria dos casos, acentua-se a preocupação com o meio ambiente, mote da campanha de Marina.

Conforme destacado na parte inicial deste texto, o tema ecologia encontra-se em disputa por vários grupos sociais, o que potencializa possíveis atravessamentos por diversas formações discursivas. No caso de Marina, percebemos nos seus enunciados marcas de Formações Discursivas (doravante FD) de diferentes origens.

As duas principais FDs que se materializam nas falas dos participantes dos programas eleitorais pertencem àquilo que estamos chamando de Discurso Ecológico do Discurso Político. Inicialmente há um contraste: tudo que provém da ecologia é tratado de forma positiva, enquanto a política é tratada como o mal a ser reparado. Esses sentidos vão sendo construídos no decorrer dos programas. Vejamos como essas questões se manifestam nos seguintes enunciados ${ }^{5}$.

E1: O uso de combustíveis fósseis para gerar energia bombeia as nossas esperanças e ilusões. Com o carbono liberado, planeta está aquecendo. Os olhos da ciência estão voltados para os pólos que estão degelando. Se nada for feito imediatamente, os oceanos vão subir 7 metros, ameaçando cidades como Rio de Janeiro, Recife e Florianópolis (...) E nós precisamos mudar agora. O Brasil tem um papel fundamental nesse processo de reequilíbrio do planeta. É possível desenvolver sem destruir, isso é ser sustentável. $(17 / 08 / 2010)$

Logo no primeiro programa, Marina já mostra seu interesse pelas questões ecológicas. Ela ancora e legitima seu discurso em argumentos que têm origem no campo científico para posteriormente trazer para o campo da política. O uso do 'nós' atesta a maneira como ela se coloca no mesmo patamar de seus interlocutores, contudo esse 'nós' é atravessado por outro discurso em que se joga a responsabilidade das mudanças

5 Os negritos nos enunciados são marcações nossas com o objetivo de destacar algum elemento. 


\section{ecd DiAno}

para a população, mas que silencia a necessidade de mudança do sistema econômico como um todo.

Dessa forma, podemos dizer que os sentidos de ecologia construídos não são sentidos de ruptura da ordem vigente, mas são sentidos que se filiam a uma FD de legitimação do sistema econômico, no qual a ecologia entraria para regular a relação homem-natureza. Ou seja, é a ecologia que baliza a cisão de Marina Silva entre o mundo social e político. É desta formação que palavras como ‘sustentabilidade’, ligada ao vocabulário ecológico, entra para a gramática política da candidata. E expressões do campo político, como 'política limpa' e 'transparência', são ressemantizadas pela FD ecológica.

E2: Reunimos as melhores cabeças do país para criar uma nova forma de fazer política. Política limpa, desenvolvimento sustentável, progresso seguro para todos. Venha fazer parte dessa equipe. Seja mais um pelo Brasil que queremos.

Com educação de qualidade para todos. Com empreendedorismo do povo brasileiro. Cuidando do dinheiro público e dos nossos recursos naturais. Só assim vamos fazer do Brasil uma liderança do século XXI (21/08/2010)

E3: Eu já vivi o pior e o melhor da saúde no Brasil. Já fui atendida como indigente e já esperei horas e horas numa fila do Sistema Único de Saúde. Meu compromisso com a saúde é mais que político, é pessoal.(31/08/2010)

Os 8 enunciados que destacamos (os dois acima e os seis posteriores) servem como demonstração de como se materializa aqui o que podemos chamar de discurso ecológico-político de Marina Silva. Suas falas são marcadas por duas caracterizações, que citamos anteriormente, a de ecologia como algo positivo, ligando seus sentidos aos de avanço e progresso. E os sentidos de política ligados ao atraso, tratada como um obstáculo a ser superado.

Um ponto que devemos destacar é o de que esses sentidos não são dados logo de cara na campanha, eles vão sendo construídos no curso desta. É o próprio fluxo do jogo eleitoral que permite à candidata construir uma rede de memória que sustenta seu discurso. Vamos nos deter em E2 e E3, já que esses dois enunciados apresentam a caracterização da política atual e como ela pode ser mudada. Em E2, Marina é 
apresentada como a 'liderança do século XXI'. Esta nova liderança se liga à FD ecológica, na qual a política será recriada pelas “melhores cabeças do país”. Esta será limpa e capaz de ser sustentável. Dessa forma, ela deveria equivaler à sustentabilidade. É aqui que começam a se ligar os sentidos de ecologia e política.

Em E3 a política se ligará a outro fator. Ela será “limpa” de instituições para servir ao povo. O compromisso não é político, é pessoal. Esta afirmação silencia todos os possíveis sentidos negativos que política poderia trazer e liga a vida pessoal da candidata ao compromisso, pois sua biografia seria maior do que a política, além de ser uma forma de se aproximar da população.

E4: Os dois candidatos que ocupam o tempo da TV quase todo fazem uma campanha de chantagem emocional. (...) Como se o povo fosse menino pronto para ser enganado. (....) Mas, cá entre nós, no Brasil real, onde a gente vive, a coisa é muito diferente. Tem fila no hospital, tem criança sem escola, tem assaltante armado na esquina. Todos os anos, na época das chuvas, pessoas morrem e milhares de famílias ficam desabrigadas (...) O que eu proponho é o desenvolvimento sustentável. É uma política diferente, tratando os problemas com sinceridade e respeito (31/08/2010) E5: Somos o país do desperdício. É água tratada que se perde antes de chegar na sua torneira. Produtos que gastam energia a toa. Lixo que poderia ser reciclado. Tempo perdido no trânsito. Mas o pior de todos os desperdícios é a corrupção. É um absurdo pagar por uma ambulância o valor de três. (...) Ainda temos o desperdício dos governos ineficientes e inchados. Nós não vamos criar mais ministérios nem obras federais desnecessárias. Vamos dar transparência a todos os gastos públicos para que a população possa acompanhar para onde vai cada centavo. Esse é o Brasil que queremos. Eficiente e sem desperdício. (07/09/2010)

Os enunciados E4 e E5 são ligados pelo elemento "Brasil Real” que ela descreve em E4, a partir dos problemas sociais e, em E5, a partir da noção de que o Brasil é a nação do desperdício. Marina é habitante desse "Brasil Real” e fala em nome das pessoas que sofrem nele. Daí o uso de 'a gente'. A resolução dos problemas é novamente construída pelo sentido político de 'desenvolvimento sustentável'. Este, situado na FD ecológica, seria capaz de resolver tanto as questões da população, quanto a sujeira política.

E6: As pessoas que assistem ao nosso minutinho aqui na TV gostariam que tivéssemos mais tempo pra apresentar nossas ideias e propostas para o Brasil. Eu quero dizer a vocês que todos os brasileiros deveriam ter esse 
direito. Acontece que estão tentando fazer dessa eleição um ringue, onde as duas grandes forças que estão aí ficam brigando para se eternizar no poder. $O$ pior é que são iguais. Defendem um tipo de crescimento sem responsabilidade com o seu futuro e o futuro do planeta. $E$ não entenderam que o país pode perder a oportunidade de se tornar uma liderança mundial do desenvolvimento sustentável. Tenho dito que é possível crescer sem destruir e preciso de mais tempo para mostrar que essa ideia é a melhor para o Brasil e para os brasileiros. (09/09/2010)

E7: O Brasil não pode se atrasar na nova economia sustentável que está surgindo no século 21. A nova força política. Tem muita gente preparada nas universidades nas empresas, na sociedade civil e também nos partidos políticos. Marina vai renovar a política brasileira. (16/09/2010)

E8: Vote em quem nunca aceitou o jogo eleitoral de cartas marcadas. Vote em quem não pratica o vale-tudo como forma de se manter no poder. Marina tem equipe, Marina tem solução para os problemas do país. $E$ é a única que pode enfrentar a corrupção e o atraso na política. (21/09/2010)

De certa forma, E6, E7 e E8 concluem e solidificam os sentidos da nova política, atravessada por uma FD de matriz ecológica que ressemantiza o sentido tradicional da política. Em E6, os sentidos de “política velha” são ligados a seus adversários na eleição. Os sentidos de transformação da política pela ecologia são afetados pelo elemento econômico, o qual vai apresentar questões de crescimento. Ele aparece, contudo, não para ser questionado, mas para ser melhorado pela ecologia.

E7 e E8 são enunciados que atestam a 'nova força política', a ‘nova política' de Marina Silva. Esta seria construída pela ecologia e pela negação da política, tida como suja. A novidade de E7 está na enumeração dos setores sociais que serão mobilizados na construção do novo governo: a expressão “melhores forças” constitui paráfrase de E1 (“melhores cabeças”). Porém, em nenhum momento se fala em movimentos sociais ligados à ecologia; em toda sua campanha Marina Silva silencia as vozes organizadas da sociedade. E8 é um enunciado de síntese de tudo que estamos analisando aqui, na mediada em que aponta para uma questão missionária da candidata.

Analisamos até aqui como a FD ecológica construiu diferentes sentidos para a política. Contudo, esta FD traz consigo também elementos de uma narrativa de catástrofe planetária. Essa perspectiva, associada à sujeira da política, maculada pela corrupção, levará a atravessamentos do campo religioso nas falas da candidata. Esse tema será tratado a seguir. 


\section{ecc DiAno}

\section{A Ecologia como redenção}

O tema ecologia, constantemente mobilizado por Marina Silva em seus programas eleitorais, vem amiúde acompanhado de uma narrativa de catástrofe atravessada por uma FD religiosa. Ao destacar a possibilidade de "fim do mundo" e a necessidade de uma "mudança imediata" que se traduziria em medidas de proteção ao meio ambiente, a candidata se apresenta como a "única liderança” capaz de evitar tais desastres. Nesse sentido, é importante recuperar o E1, o qual nos deixa entrever como esses elementos se articulam na fala de Marina.

E1: O uso de combustíveis fósseis para gerar energia bombeia as nossas esperanças e ilusões. Com o carbono liberado, planeta está aquecendo. Os olhos da ciência estão voltados para os pólos que estão degelando. Se nada for feito imediatamente, os oceanos vão subir 7 metros, ameaçando cidades como Rio de Janeiro, Recife e Florianópolis (...)E nós precisamos mudar agora. O Brasil tem um papel fundamental nesse processo de reequilíbrio do planeta. É possível desenvolver sem destruir, isso é ser sustentável. (17/08/2010)

O E1 traz um tom advertência e enfatiza a necessidade de que mudanças sejam realizadas “imediatamente”, “agora”. Como vai se verificar nos programas que seguem a este, uma mudança é condição necessária (quiçá, suficiente) para que outras ocorram. Assim, Marina se apresenta como essa liderança, que emerge do povo para impedir uma catástrofe planetária. Tais articulações permitem-nos perceber um atravessamento entre uma FD ecológica e outra religiosa por meio de elementos como a narrativa de fim de mundo e o messianismo.

É importante notar que discursos não são puros em sua natureza, mas, pelo contrário, formam-se dos atravessamentos e tensionamentos que existem entre si. As preocupações com o meio ambiente estão intimamente ligadas em sua base a questões de caráter religioso. Nas primeiras religiões politeístas, a incorporação do mundo da divindade ao mundo do humano fazia com que se tivesse um profundo respeito pela natureza. Destruir o ambiente natural que os cercava significava profanar a morada dos deuses (ELIADE, s.d). Proteger o meio ambiente não era apenas uma necessidade, mas uma obrigação. 
Com o monoteísmo, esta relação se modifica, uma vez que a divindade deixa de ocupar um lugar integrado ao mundo dos homens. Isso provoca um certo distanciamento entre as preocupações de âmbito religioso e as questões ecológicas. No entanto, nos últimos anos, o que temos observado é uma reaproximação no campo discursivo do ecológico ao religioso pelas narrativas de fim de mundo, recorrentes em quase toda religião. No caso analisado, encontramos outro elemento que viabiliza essa aproximação: o caráter messiânico. Isto fica claro nos momentos em que ela se coloca como a única liderança capaz de evitar as catástrofes anunciadas.

E9: Na luta contra Golias, o pequeno Davi tinha apenas uma pedra. Você
pode fazer do seu voto a pedrinha capaz de vencer a luta contra a
violência, o descaso, a devastação. É você que decide o futuro do Brasil.
Essa vitória é sua. (23/09/2010)
E10: O Brasil deu grandes passos em sua história quando seus líderes
tiveram uma visão estratégica. Foi assim com a construção de Brasília,
com o Plano Real e com o Bolsa Família. Agora precisamos manter o que
já conquistamos e dar mais um passo: colocar o Brasil no século 21,
completar o crescimento econômico e social com o uso inteligente das
riquezas naturais. (25/09/2010)

No E9 encontramos a única referência direta que a candidata faz à Bíblia ou a personagens pertencentes ao universo religioso, caso da história de “Davi e Golias”. Importante destacar que a candidata tinha profundas ligações com os evangélicos, sendo que estudos como o de Ricardo Mariano (1999) demonstram uma mudança no envolvimento destes com a política. De acordo com o autor, os grupos de vertente pentecostal passaram de uma posição de rejeição à política para uma postura conhecida pelo emblema “irmão vota em irmão”.

No caso em questão, percebemos que, embora Marina Silva não seja apresentada como a candidata apenas dos evangélicos, há marcas discursivas que atravessam os programas da candidata que remetem a uma FD religiosa. No E9, além da referência explícita à Bíblia, vemos novamente acentuada a questão da liderança que emerge no seio do povo para redimi-lo. Se o voto de cada um pode ser a "pedrinha” que vai derrubar o "gigante” (Serra e Dilma), Davi corresponderia à própria Marina Silva, que "salvaria o futuro" do Brasil. 


\section{míDiA

É interessante notar como as FDs ecológica e religiosa se atravessam em um mesmo enunciado. No E9, vemos se aproximarem significantes como "violência", “descaso” e “devastação”. Os três são significantes recorrentes quando se trata do meioambiente. O último chama a atenção por seu teor de catástrofe, o que nos permite relacionar com a narrativa de "fim de mundo", comum ao universo religioso e ecológico.

No E10, novamente o papel das lideranças é destacado. Este é o único momento dos programas de Marina Silva que ela reconhece possíveis avanços alcançados por administrações diretamente ligadas aos candidatos adversários. Em outras edições, as referências são sempre negativas. É curioso observar que os feitos são ligados aos líderes e não aos partidos dos quais estes fazem parte. Assim, coloca-se a questão partidária e ideológica em segundo plano e enfatiza-se a competência pessoal. E, dessa forma, Marina se coloca como a nova liderança, capaz de fazer as mudanças que o Brasil precisa neste momento e que se traduz por uma nova política, a "política limpa”, “ecológica”.

\section{Conclusão}

Apesar do curto tempo que Marina possuía na TV, seu "minutinho" foi de extrema importância para tornar as ideias da candidata conhecidas nacionalmente. Vale lembrar que a campanha da candidata do PV possuía uma verba bem limitada se comparada a dos outros candidatos. Nos programas veiculados no Horário Eleitoral, as pessoas eram convidadas a transformar suas casas em "casas de Marina”, que funcionavam de modo semelhante a um comitê político.

Marina veio com uma proposta de ser a “novidade” daquela eleição e a votação expressiva que a candidata obteve demonstra que, em alguma medida, ela obteve sucesso. No tocante à temática dos programas, embora a tabela apresentada indique uma presença maior do tema "ecologia”, não se pode afirmar que a candidata foi monotemática. Não obstante, as referências à ecologia eram constantes. Ainda que 


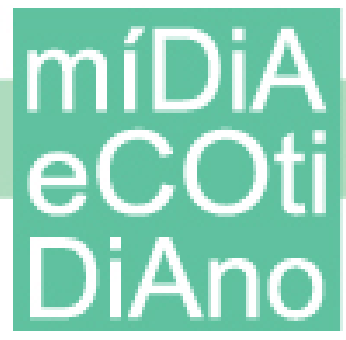

não falasse diretamente, temas como a “disputa eleitoral”, “saúde” e “educação” eram significados sob o signo da ecologia.

Conforme foi indicado na primeira parte deste trabalho, a questão ecológica viabiliza uma série de diferentes alinhamentos discursivos, o que, em grande parte, se deve aos atores que disputam a “ecologia”, quais sejam: cientistas, movimentos sociais, empresários e políticos. No caso de Marina, percebemos uma clara aproximação com o setor empresarial pela questão do “desenvolvimento sustentável” e pelo notável silenciamento dos movimentos sociais. Em nenhum dos programas encontramos depoimentos de membros de Ongs ou de ativistas.

Por outro lado, a presença de artistas, empresários (como seu vice) e professores universitários era uma constante. A participação popular se dava por denúncias e perguntas que a candidata respondia em estúdio, outro elemento que aponta para certo distanciamento em relação à população. Isso contrastava com uma tentativa de se provocar algum tipo de identificação com as origens "humildes” de Marina. Ao mesmo tempo em que ela se colocava entre "as melhores cabeças” da política, das universidades e das empresas, Marina se posicionava também como “a” liderança popular.

Esse caráter messiânico sugerido pelo atravessamento de uma FD religiosa nos enunciados casa com a narrativa de catástrofe que aparece amiúde quando se trata de questões relacionadas à destruição do meio ambiente e que se busca, em alguma medida, relacionar à política adotada por seus adversários. "Política suja”, “corrupta” e “ineficiente”, responsável pelo perigo que se avizinhava, segundo Marina Silva. Enquanto isso, a candidata se colocava no extremo oposto. Dessa forma, significantes como “eficiência”, “política limpa”, “desenvolvimento sustentável” se associavam à figura de Marina Silva.

A título de uma consideração final, mais do que de uma conclusão, podemos afirmar que os programas de Marina Silva, na sua textualidade verbal, mais do que girar em torno da ecologia, foram significados ecologicamente. Uma "política ecológica” que, ao se aproximar dos setores empresariais, distanciava-se concomitantemente dos movimentos sociais e de uma política de esquerda, berço político-ideológico da 


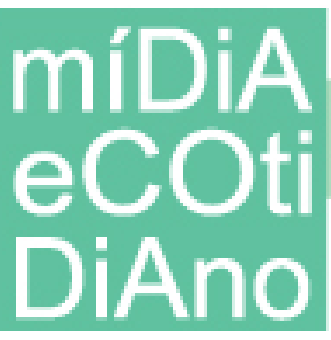

candidata. Seria interessante pensarmos também de que modo essas “pistas” ideológicas que encontramos nas textualidades verbais aparecem (ou não) em outras materialidades, como o corpo e a imagem, bem como o modo como estas se afetam/ se relacionam. Mas esta é uma proposta que deixamos aqui apenas sugerida e que pretendemos abordar em trabalhos futuros.

\section{Referências}

ALEXANDRE, Agripa de Faria. A perda de radicalidade do movimento ambientalista brasileiro uma nova contribuição à critica do movimento. In: Revista do Mestrado em Educação Ambiental da UFRG, vol. 10. Porto Alegre, 2003. Disponível em: http://www.seer.furg.br/ambeduc/article/view/899 Acesso: 15/08/2012

CASTELLS, Manuel. O poder da identidade. 5. ed. São Paulo: Paz e Terra, 2006.

DIAS, Célia Regina da Silva. As antinomias discursivas da Ecologia Política: uma análise baseada na experiência do Partido Verde no Rio de Janeiro, 1986-1992. In: ALIMONDA, Héctor (org.) Ecologia e Política: Naturaleza, Sociedad y Utopia. Buenos Aires, Ed CLACSO, p. 101-114, 2002. Disponível em: http://168.96.200.17/ar/libros/ecologia/dias.pdf Acesso: 20/08/2012

ELIADE, Mircea. O sagrado e o profano: a essência das religiões. Lisboa (Portugal): Edição Livros do Brasil, s.d.

GÓES, Ione. Movimentos ambientalistas: Trajetória Histórica. Disponível em: www.juvencioterra.com.br/virtual/texto_ambientalistas.doc. [s.d] Acesso: 20/09/2011.

MARIANO, Ricardo. NeoPentecostais: sociologia do novo pentecostalismo no Brasil. São Paulo: Loyola, 1999.

ORLANDI, Eni P. Análise de discurso: Princípios e Procedimentos. Campinas: SP, Pontes Editores, 2005.

PÊCHEUX, Michel. O discurso: estrutura ou acontecimento. Tradução: Eni Pulccinelli Orlandi. 2. Ed.. Campinas: SP, Pontes, 1997. 